\title{
DETECTION OF SOIL MOISTURE CONTENT AS A TOOL FOR ANTHROPOGENIC IMPACT
}

\author{
Ahmed Abdelhalim \\ Geology Department, faculty of science, Cairo University, Egypt \\ Contact E-mail: ahmedabdelhalim@cu.edu.eg
}

\begin{abstract}
Recently, spatial analysis has taken place as a tool to detect the environmental changes and understanding the anthropogenic impacts in different scales and times. One of the effective remote sensing techniques is spectral indices algorithm which is used to differentiate preciously between different land cover elements. In this paper the moisture an index is applied on the multispectral Landsat satellite images Thematic Mapper (TM) to detect the soil moisture changes during different time series. Four launched years (1990, 2001, 2009, and 2016) of satellite image are used for the north coast of the Kuwait Bay which is occupied by the desalination Al-Subiya plant. The impact of the anthropogenic desalination plant on the coastal area was recognized and the increase of saturated area is classified into four ranks from low to high. The created maps show that the outlet channel had changed from water to high moisture assigned class that indicates the accumulation of a considerable amount of deposits as a result of neglecting channel maintenance.
\end{abstract}

Keywords: Moisture index, desalination impact, change detection, remote sensing technique

\section{INTRODUCTION}

Coastal countries such as Arabian Gulf countries have limited freshwater resources. Therefore, the main human activity along the gulf coast is dominated mainly by extensive use of seawater for sustainable development purposes that led to build numerous desalination plants to provide the domestic needs. one of the most promising areas for development is the northwest part of Kuwait Bay, which is named Khor Al Subiya where the Al Subiya power technology plant is constructed at year 2000 (Fig. 1).

In general, the desalination of seawater offers several environmental benefits but also, it is accompanied by negative anthropogenic impacts on the nearby coastal area (Einav et al. 2002, Mohamed 2009, and Al Dousari, 2009). Furthermore, the earth observations and spatial analysis by using images acquired from the satellite sensors are widely applied in large areas such of coastal zones dominated offshore and onshore environment (Fitzpatric 1987 and Franklin and Wulder 2002). Moreover, the good start point to understand relevance between dynamic changes and human activates is initiation of a different scale and time of socio-ecology information (Anderies et al., 2004; and Houpin 2010). Accordingly, in this paper the optical satellite data have been processed and analyzed to find out the changes of moisture content of north of Kuwait Bay including Ras and Khor Al-Subiya in time period of about 25 years which reflected its anthropogenic impact on coastal land.

Geologically; the case study area is a part of NW coastal plain of Kuwait Bay which dominated quaternary deposits. These deposits composed mainly of gravels and unconsolidated marine sand, silt clay and supra-tidal sabkha surfaces (Milton (1967) and Khalaf et al. (1984), and El-Baz and Al-Sarawi (1996)).

Geomorphologically; the study area dominated by a tidal flat, shoaling sand, muddy flat, sabkha, sand beach and desert surface (Fig. 1) (Khalaf and Al-Hashash (1983). 
Fig. 1:

Geomorphological map of Kuwait State including the location of study area (modified after Al Sulaimi and El Rabaa, 1994).

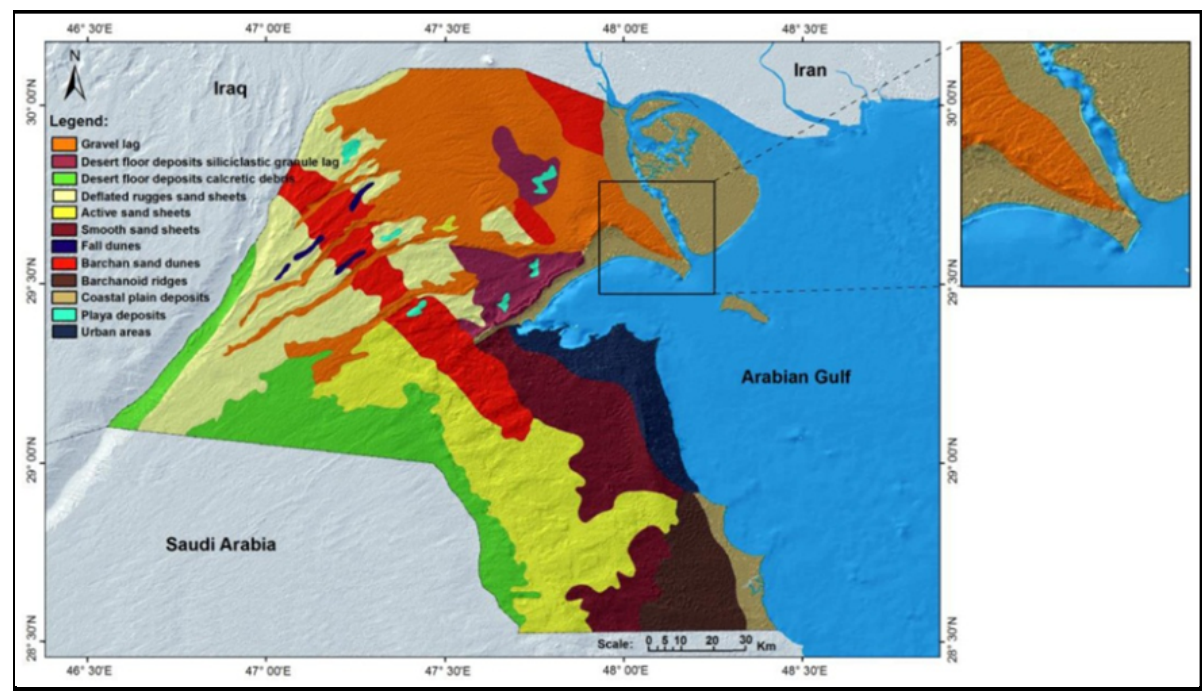

\section{METHODOLOGY AND IMAGE PROCESSING}

\section{Data preparation}

Different techniques of image enhancement were applied by using ENVI 5.3 software to enhance the visualization of area features. However, the raw satellite image was acquired in individual wave length channels; all these bands were stacked in one image and geocoded into UTM Zone 39 North projection with WGS-84 datum. Additionally the radiometric enhancement technique was applied to ensure radiometric balance between individual scenes, and remove any atmospheric noises. This step was followed by a synchronize technique to adjust the color balance and boundary of all four time series images $(1990,2001,2009,2016)$ used in change detection. However, the maps that were produced based on TM are managed on ArcGIS10.4.1 to produce a different map types and scales.

\section{Moisture index}

Due to the lack of monitoring information of the countryside of northwest coast of Kuwait Bay and missing of an easy access data providing the different changes and expected future scenarios, the spatial monitoring using spectral reflectance characterization of available satellite image bands are used to create band ratios and different indices. Such indices and its relative algorithms in image processing software are extensively used in the discrimination of different land cover classes of vegetation cover, water surface, land water mask, ores, and rock units separately (Birth and McVey 1968, Rouse et al. 1973, Sultan et al. 1986, Giltelson et al. 1996, Carroll et al. 2009, and Abdelhalim 2013, Zoher et al. 2019). In addition, the moisture content and index could be created by using the wavelength and spectral reflectance character of satellite bands in specific mathematical formula. A common formula of Normalized Difference Moisture Index (NDMI) is developed by (Skakun et al. 2003) using TM bands is, $(\mathrm{NDMI})=(\mathrm{NIR}-\mathrm{MIR}) /$ (NIR+MIR).

In this study the Normalized Difference Moisture Index (NDMI) derived from spectral bands 4 and 5 of time series Landsat TM is calculated as follows, NDMI = [Band $4-$ Band 5] / [Band4 +Band 5]

The NDMI formula is applied on four images of different dates of years 1990, 2001, 2009, and 2016 to derive that index in six classes ranging from low, low-medium, medium, high, beside water surface (Fig. 2 and 3).

\section{Shore line}

Because the penetration of light through water body is inversely proportional to its wavelength, while the shorter the wavelength the higher the penetration (Lillesand et al. 2003), the Band 7 of TM satellite data, which represents the short wave infrared (SWIR) is used to delineate the shoreline boundary. The ENVI software provided the color slice algorithms that are used to discriminate between land and water 


\section{Detection of soil moisture content as a tool for anthropogenic impact}

surfaces. The time series images used are the land sat image dated just before the plant construction and the most recent one of years 1990 and 2016 respectively. The shoreline changes were examined by using ArcGIS software by creating an overlap shoreline layers (Fig. 4).

\section{RESULT}

The resulted images (Fig. 2) show distinct changes in moisture content in Ras Al-Subiya Peninsula. These changes monitored and detected the influences of Al-Subyia power plant on the nature of sediments and intertidal flat.

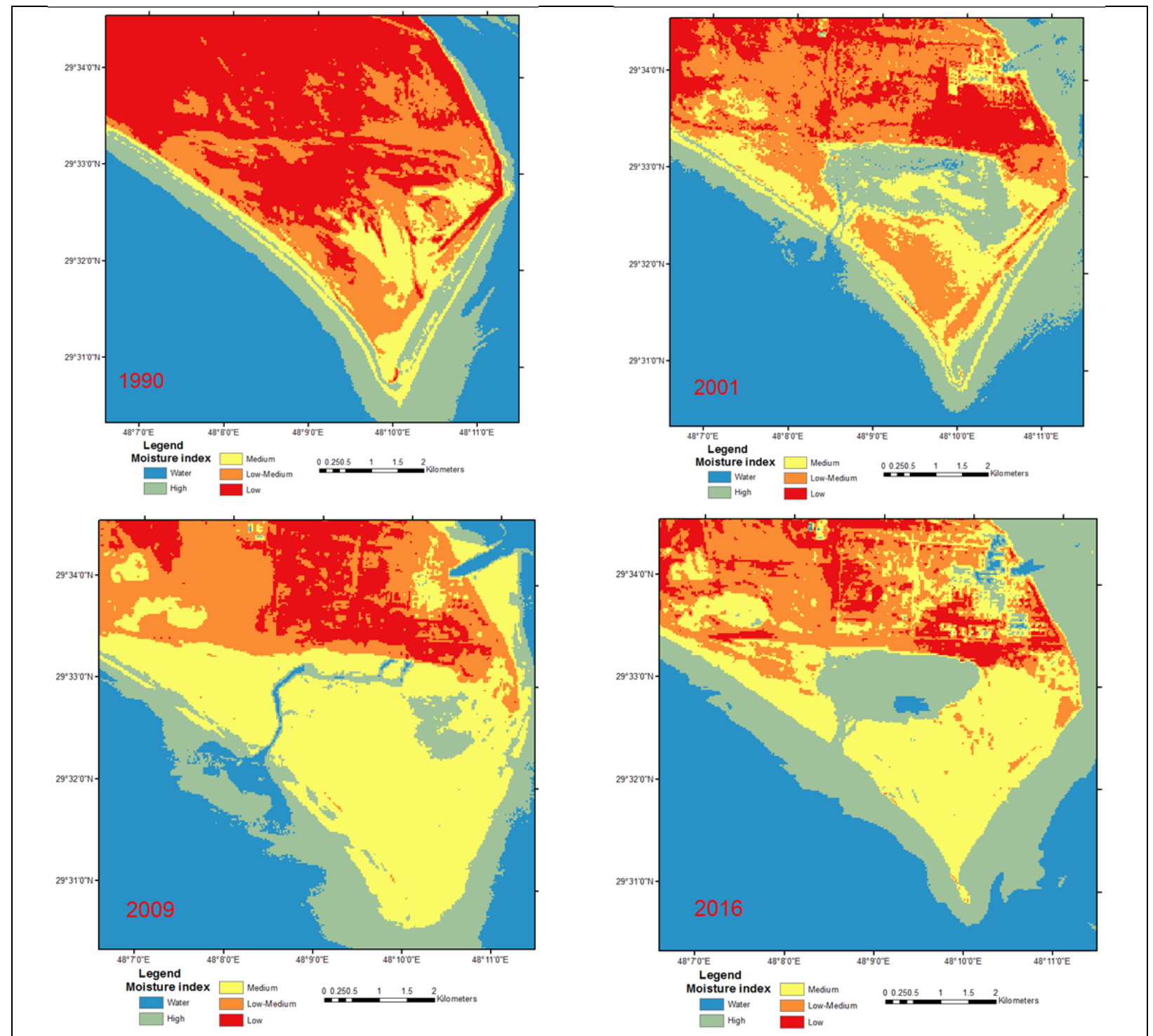

Fig. 2: Normalized Difference Moisture Index (NDMI) content of four-time series images (1990, 2001, 2009, and 2016) shows the changes of moistures and wet areas before and after construction of power plant in outlet muddy flat.

The results indicates that the area before power plant construction (1990) appeared in medium to low moisture except the beach triangular area is represented as high moisture. After the Al-Subiya power plant started the desalinization process, the moisture index was calculated for years 2001, 2009, and 2016 (Fig. 3). In year 2001, an irregular shape of high moisture content is observed in the central part of the Ras AlSubiya peninsula, while the beach zone has no changes. In year 2009, the outlet channel is well represented and the moisture signature is merely the same (medium to high) except a parcel of salt marsh 
Abdelhalim, A.

in the middle west of the intertidal tidal flat area. In year 2016, the outlet channel changed from clear water to high moisture that means, the big amount of deposits suspended in the outlet channel were participated. For that reason, the channel should be excavated (cleaned) periodically from time to time. On the other hand, the rest area is represented by medium moisture, even the area around the Al Subiya power station buildings changed from high to moderate moisture content.

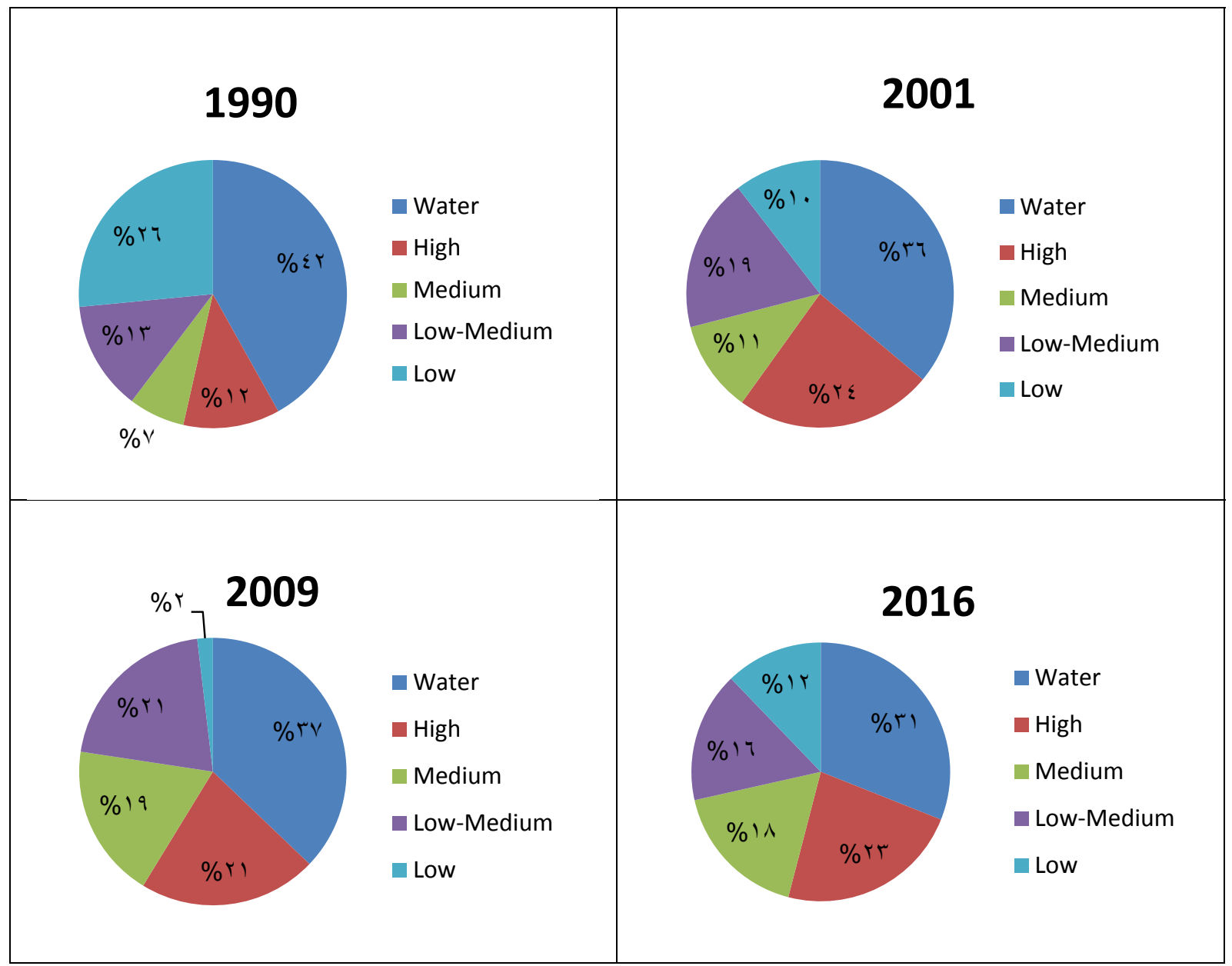

Fig. 3: Statistical analysis of each assigned moisture index for time series (1990. 2001, 2009, and 2016).

\section{DISCUSSION}

To verify the above results mentioned from the application of the Normalized Difference Moisture Index (NDMI), following the recent environmental problem of the global warming and sea level rising phenomena. This study recommended detecting the shoreline changes and discussing its influence on the moisture content in area under concern (Fig. 4).

Consequently, The total area covered with water in 1990 reached to about $432 \mathrm{~km} 2$ and in 2016 about $434 \mathrm{~km} 2$ that increased by about two km2. Such increasing in surface water put a question of what are the factors influenced the sea and shoreline changes. Regarding the field observations and satellite visual interpretation there are two possible main reasons. The first is because the human activity, which mainly from Ras Al-Subiya power plant the second may be mainly related to the global warming and sea level rising. Besides these two reasons, the occasionally coastal erosion by wave action, tidal-wave currents, and intertidal channels are considered as ordinary natural factors. 
Detection of soil moisture content as a tool for anthropogenic impact

Fig. 4: Statistical analysis of each assigned moisture index class for time series (1990. 2001, 2009, and 2016).

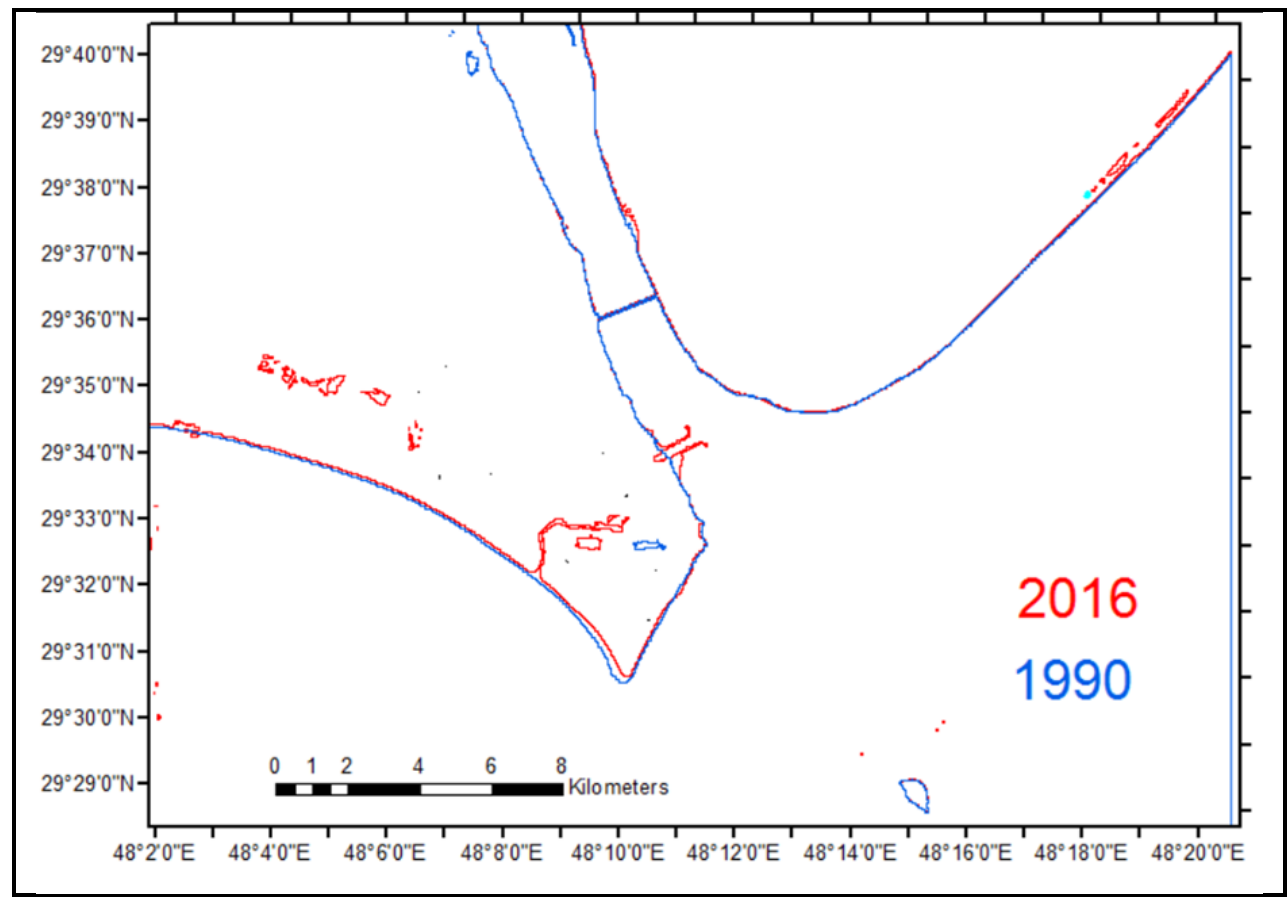

\section{CONCLUSION}

The application of moisture indices to delineate the relation between the anthropogenic activities and the moisture content is preferred in desalination plant sites. Therefore, the study of shoreline changes and coastal geomorphology in different time scale provide the understanding of the environmental impact of natural and anthropogenic factors affecting the land and water surfaces. The satellite images in different time series of years (1990, 2001, 2009, and 2016) have been processed and analyzed to find out the north area of Kuwait Bay including Khor and Ras Al-Subiya and Bubian Island changes. Consequently, the spatial analysis and change detection by using time series satellite images, of shoreline and moisture content of Al-Subiya area show the dynamic changes of plant outlet channel and its impact on moisture content on Ras Al-Subiya. Where, the outlet channel changed from clear water to high moisture that points to the accumulation of a considerable amount of deposits suspended in the outlet channel that necessitates periodical maintenance.

\section{REFERENCES}

Abdelhalim, A. (2013): Implementation of land-use-cover change Analysis into megacity management Response by using the DPSIR model. Aachener Geographische Arbeiten - 50 / 2013 S97 - 114.

Al Dousari, A. E. (2009): Desalination leading to salinity variations in Kuwait marine waters, American Journal of Environmental Sciences, 5(3), 451-454.

Al-Sulaimi J. and El-Rabaa, S. M., (1994): Morphological and morphostructural features of Kuwait. Geomorphology, 11, 151-167.

Anderies, J. M., Janssen, M. A. and Ostrom, E. (2004): A framework to analyse the robustness of social ecological systems from an institutional perspective. Ecology and Society, 9(1), Art 18.

Birth, G. S., and McVey, G. R. (1968): Measuring the color of growing turf with a reflectance spectrophotometer. Agronomy Journal, 60, 640-643.

Carroll, M., Townshend, J., DiMiceli, C., Noojipady, P., Sohlberg, R. (2009): A New Global Raster Water Mask at 250 Meter Resolution. Inter. J. Digital Earth, 2(4), 291-308.

Einav, R., Harussi, K. and Perry, D. (2002): The footprint of the desalination processes on the environment, Desalination, 152, 141-154. 
Abdelhalim, A.

El-Baz, F. and Al-Sarawi, M. (1994): Kuwait as an alluvial fan of a paleo-river. Reprinted from Z. GEOMORH. N. F. Suppl.-Bd. 103, 49-59.

Fitzpatric, L. (1987): Producing Alaska Interim Land Cover Maps from Landsat Digital and Ancillary Data. In Proceedings of the $11^{\text {th }}$ Annual William T. Pecora Memorial Symposium: Satellite Land Remote Sensing: current programs and a look into the future American Society of Photogrammetry and Remote Sensing, 339 - 347.

Franklin, S. E. and Wulder, M. A. (2002): Remote sensing methods in medium spatial resolution satellite data land cover classification of large areas. Progress in Physical Geography, 26(2), 173-205.

Gitelson, A., Kaufman, Y. J. and Merzlyak, M. N. (1996): Use of a green channel in remote sensing of global vegetation from EOS-MODIS. Remote Sensing of Environmenta, 58, 289-298.

Houpin, S. (2010): Urban mobility and sustainable development in the Mediterranean Regional diagnostic outlook. United Nations Environment Programme Mediterranean Action Plan, report, 16-18.

Khalaf, F. I. and Al-Hashash, M. (1983): Aeolian sedimentation in the north western part of the Arabian Gulf. Journal of Arid Environments. 6, 319-332.

Khalaf, F. I. Gharib, I.M. and Al-Hashash, M. (1984): Types and Characteristics of the Recent Surface Deposits of Kuwait, Arabian Gulf. Journal of Arid Environment, 7, 9-33.

Lillesand, T .M., Kiefer, R. W. and Chipman, J. W. (2003): Remote sensing and image interpretation (5th ed.). Wiley publication. ISBN 0-471-15227-7, (Introduction and chapter 3).

Milton, D. E. (1967): Geology of Arabian Peninsula, Kuwait. U.S.G.S Prof. Paper 560E.

Mohamed, K. A. (2009): Environmental impact of Desalination Plants on the environment, Hurghada, Egypt: Thirteenth International Water Technology Conference, IWTC 13.

Rouse, J. W., Haas, R. H., Schell, J. A. and Deering, D. W. (1973): Monitoring vegetation systems in the Great Plains with ERTS. In3rd ERTS Symposium, NASA SP-351 I, 309-317.

Skakun, R. S., Wulder, M. A. and Franklin, S. E. (2003): Sensitivity of the thematic mapper enhanced wetness difference index to detect mountain pine beetle red-attack damage. Remote Sensing of Environment 86, 433-443.

Sultan, M., Arvidson, R.E. and Sturchio, N. C. (1986): Mapping of serpentinites in the Eastern Desert of Egypt by using Landsat thematic mapper data. The soc. Am. Geol. December, 14(12), 995-999.

Zoheir, B., Abd El-Wahed, M., Pour A. B. and Abdelnasser A. (2019): Orogenic Gold in Transpression and Transtension Zones: Field and Remote Sensing Studies of the Barramiya-Mueilha Sector, Egypt. Remote Sens., 11, 2122, 1-33. 


\section{Detection of soil moisture content as a tool for anthropogenic impact}

$$
\begin{aligned}
& \text { الكشف عن محتوى رطوية التربة كأداة للتأثير البشري } \\
& \text { احمد عبد الحليم } \\
& \text { قسم الجيولوجيا - كليه العلوم - جامعه القاهره } \\
& \text { الخلاصة }
\end{aligned}
$$

في الآونة الأخيرة ، تم إجراء التحليل المكاني كأداة لاكتثاف التغيرات البيئية وفهم التأثيرات البشرية المنشأ في مختلف المقاييس والأوقات ـ واحدة من تقنيات الاستشعار عن بعد الفعالة هي خوارزمية المؤشرات الطيفية التي تستخدم للتمبيز الثمين

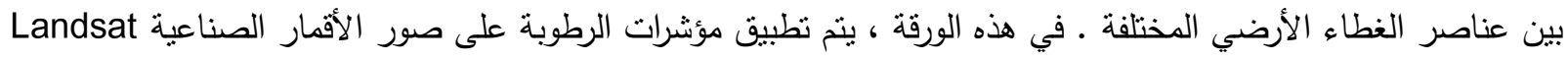

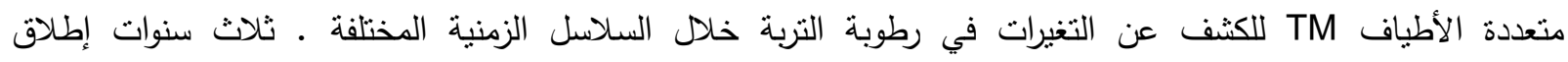

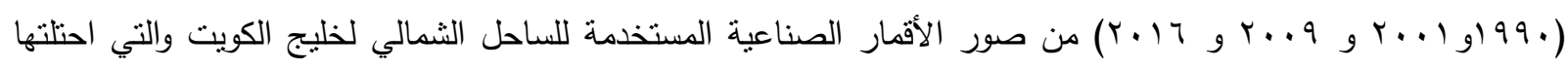

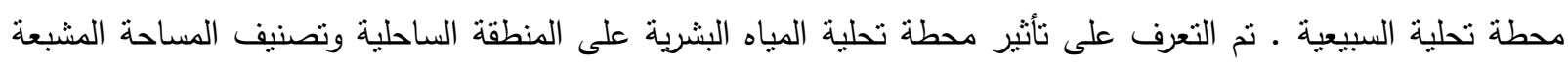

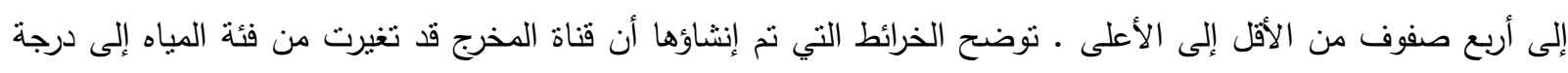

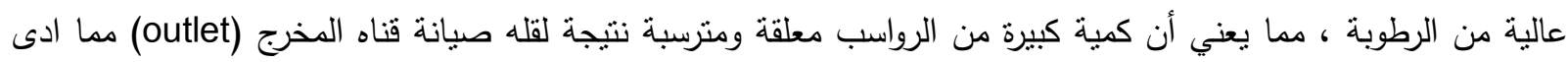
لتشبع التربه بمخرجات المحطه مع الزمن. 